\title{
MODEL DESIGN OF THE INFRASTRUCTURE LAYER OF POSTAL SYSTEM
}

The idea and purpose of this article reside in addressing the postal system model by decomposing into independent subsystems in the form of displaying through a layered network model. Postal service is generally seen as a sequence of processes for collecting and distributing shipments for the purpose of their delivery. This service can also be defined as service guaranteeing functions in identified layers of the postal system. This allows to identify the functions and protocols for mutual communication and interoperability between different postal systems including solutions of issues of regulation.

Keywords: Interoperability, postal system, layer model, the network layer, infrastructure.

\section{Introduction}

Definition of the postal services sector, clear identification of postal markets, is not easy given the diversity and overlapping of the various categories of services. One possibility, however, is to look at these services in terms of their normative and regulative definitions. It is a typical approach to understanding postal services by dividing them into the category of universal and other services with the determination of their basic characteristics and conditions of their provision. In this sense, the postal service is characterized by a high degree of spatial and temporal availability and in regulated segment also by price affordability. Main characteristics including quality indicators are normative defined with a clear determination of the minimum standards of fulfillment. In the segment of mandatory (universal) services this fulfillment must be monitored. Normative and regulative aspects when defining and assessing the postal services are often supplemented by an analysis of the entire postal industry value chain, which includes four basic activities of the postal service. Such a definition of postal services is also obvious in the evaluation reports of the European Commission in [1 and 2] or in professional reports and discussions of many authors in [3 - 5]. It is a view on the postal services in terms of analysis of processes and sub-processes that are implemented in networks. This view has been recently significant, particularly in addressing issues of interoperability and of regulation of access to the public network. Looking for points suitable for third-party access to the postal system is closely related to the nature of the postal infrastructure and network processes. These processes are labor intensive and are also characterized by daily, direct contact with customers, which is intrinsically linked to the quality of services.

Network nature of postal services does not differ from other network systems. There is obvious overlap of common features with transport or telecommunications systems whether in the design and organization of the networks or in requirements for coverage of territory, particularly with regard to regulated services of general public interest. At a certain level of abstraction, a complex postal system can be seen in layers, as is the case of telecommunications services and systems. In both cases, when using a layered model, it is possible to consider the existence of the same input elements of system: forwarder and receiver/ addressee, infrastructure as network nodes, available transmission path and means of transport as a transfer medium. It remains to determine the number of layers and functions to ensure the required communication services [6].

\section{Objective and methodology}

Since the service can be understood as ensuring the process to meet customer requirements on the one hand and to make a maximum legitimate profit on the other hand, postal system can be illustrated in the context of the layers. The legitimate profit is used for the growth of provider of these services. The aim of this

\footnotetext{
* ${ }^{1}$ Lucia Madlenakova, ${ }^{1}$ Radovan Madlenak, ${ }^{2}$ Anna Rudawska

${ }^{1}$ Department of Communications, Faculty of Operation and Economics of Transport and Communications, University of Zilina, Slovakia ${ }^{2}$ Faculty of Mechanical Engineering, Lublin University of Technology, Lublin, Poland

E-mail: Lucia.Madlenakova@fpedas.uniza.sk
} 
paper is to highlight the determination of the functions of the layers of postal system. At the same time, the paper highlights the definition of rules for communication between peer layers and determination of the interface between the layers, so that the model meets the requirements of open postal system which allows the interoperability with other systems in the functions and roles of the various layers of the postal system. Interoperability is particularly important in the network of the system, which is crucial in terms of implementing postal service. The methodology of modeling functions, tasks, interfaces and protocols is based on an analysis of principles of OSI Reference Model [7].

\section{Results and discussion}

Determination of the functions of each layer in the model is based on assumptions of underlying network arrangement of postal system. According to the pattern of open communication system OSI, which is standard, it is not compulsory to use a particular type of technology or equipment. It is about providing guidance on where it is necessary to ensure consistency in communication and to set the rules for the interconnection of networks. We consider the model divided into three layers (Fig. 1).

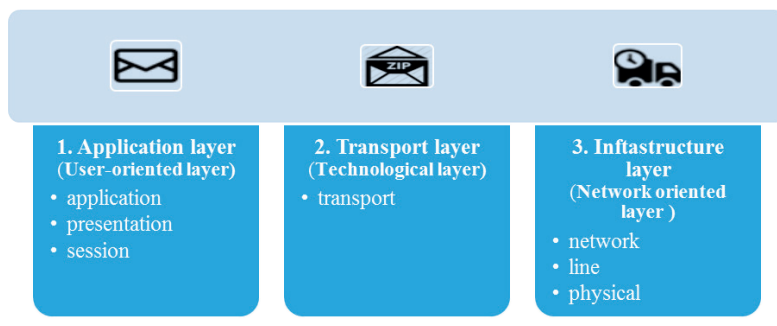

Fig. 1 Three-layer model of postal system

User-oriented layer mediates customer's contact with the postal system through equipment allowing a consignment to enter into the postal system at the collection stage and to exit from the postal system at the delivery stage. During the whole technological process of implementation of the postal services in justified cases (depending on the type of service and technology used) it is allowed to use the application services to monitor the movement of shipments. Technological layer ensures decisions on the use of appropriate techniques according to the requirements of the service provided at all stages of the postal service.

The infrastructure layer of the postal system decides about the physical transfer of shipments and provides these shipments. It necessarily covers all stages of the transfer process from the collection of consignment until its delivery. This layer provides the activities realized in stationary and mobile objects, which operate as traditional access and contact points of network (endpoints) but also as the processing centers. The infrastructure layer necessarily carries out activities related to the entry of shipments into the postal system from extraneous postal system, thus at the moment of permitted access of other postal operator to the network. In the process of transfer of shipments, infrastructure layer functions affect activities related to the use and movement of mobile device along the specified transport path. In the phase of sorting of consignments, infrastructure layer functions affect activities carried out in the processing centers, whose task is not only to sort consignments based on the tasks resulting from the technology layer of the network, but also to access the network for processing of consignments coming from external postal systems. At the delivery stage infrastructural layer works again in stationary or mobile devices. It performs activities related to the exit of consignments from the postal system [8].

\subsection{Description and tasks of the infrastructure / network layer of postal system}

Infrastructure (network) layer appears in terms of determining the functions of the postal system as the most important. Determination of its functions also allows the solution of important attributes relating to access and connection to the networks of individual operators or thinking about ways of construction and organization of postal transport networks.

General functions of the network-oriented part of model are: - utilization of available infrastructure and the relevant types of transport to ensure the transport of postal substrate,

- creating of topological links between existing network nodes, creating links between two adjacent nodes,

- addressing, routing and route location of consignment/ shipping units to their destination.

Network-oriented part of layer model is actually associated with physical distribution of consignment, for which it uses existing infrastructure and real transmission medium as an operational postal rate [8].

\section{The functions of the infrastructure layer}

1. Network part of infrastructure layer is seen as an aggregate of equipment and physical media, which together form an autonomous entity available to the interconnection of postal systems to ensure the transport of postal substrate through the establishment of fixed route on the basis of identification element, which may be a direction sign determining the routing in each point of the network.

- The task is to provide means for the implementation of the connection and transport of consignment between the individual postal systems.

- It ensures the establishment of connection through a variety of configurations from simple two-point connection to a network connections supported by a complex combination of subnetworks, which are offered by a line section of the infrastructure layer. 
Basic service provided to the technology layer: providing of transparent shipment so that the structure and content of the transport units of postal substrate is determined only by the layers above network layer. The network part of the infrastructure layer provides the functions necessary for hiding the differences of used transportation technologies of individual postal systems. This creates a consistent network service. Thus, the service provided at each end of the network connection is the same even if the network connection is established by means of several subnetworks with different types of processing or by various means of transport from which this connection is independent. The exception is the level of quality of individual sub-networks or means of transport.

Services provided by network part of infrastructure layer are as follows:

- transport of postal substrate in the prescribed form through selected network path,

- addressing in the network according to the identification element (identifier),

- creation of network connections from point to point,

- ensuring the quality of provided service,

- local detection of errors.

Protocol: network address - directional sign that uniquely identifies each of the end systems (to ensure access to the subnetwork, or the network of other postal system).

Interface: a node in the network.

Quality: depends on agreement between the technological layer and services of infrastructure layer in selecting paths in the network, which will be the same at the endpoint as declared at the start. It is about fulfillment of parameters such as: availability, reliability, network capacity, speed, error rate. Safety: Safety services related to the provision of service of network part of infrastructure layer from one end system to another end system are the same as in providing access to the sub-network or other network [9]. In particular it is about:

- identifying the point of origin of postal substrate / consignment,

- secrecy of connections between nodes (ending nodes),

- confidentiality of transported flows,

- integrity of relocation.

2. Line part of the infrastructure layer provides the functional and procedural means for creation of physical connections between network nodes. It decides about joining of two adjacent nodes, and creates a network typology. Functions and services provided for network part:

- mapping of postal substrate,

- identification and exchange of postal substrate,

- control of interconnection of systems - ability to manage interconnection of nodes in the physical part of the infrastructure layer,

- detection of errors on transport units,
- routing and transport of postal substrate between two points,

- sorting, consolidation and deconsolidation of transport units and aggregates,

- control of flows between nodes,

- detecting or correcting errors that may occur in the physical part of the infrastructure layer.

Protocol: rules to control flows between nodes (transport order, postal traffic plan, timetable ...).

Quality: network capacity, the transportation time (a failure), error related to incorrect delivery of consignment and so on.

Safety: Safety protection is always carried out before the performance of the common functions in this part of the infrastructure layer: before dispatch of consignment in the flow and through ordinary layered functions - after acceptance of delivery in the next node (confidentiality of relocation) [10].

3. Physical part of the infrastructure layer provides the means for activating a physical - real connection of nodes in the network to ensure the transport of postal substrate between nodes in the network. The physical connection may also include other systems, each of these systems provides transportation of the postal substrate by means of the relevant transmission media (postal course) [11]. The functions in the physical part of the infrastructure layer are determined by the characteristics of used transmission medium and may be different:

- activation and deactivation of the physical link,

- transport of postal substrate - identification, loading and transport.

Protocol: Its role is to ensure administration and management of a physical connection (postal traffic plan, transport order, timetable...).

Interface: storehouse / loading ramp.

Quality: is derived mainly from used topological connections of nodes in the network and used transport [12]. It can be characterized by parameters:

- error rate - errors relating, for example to a loss of a consignment,

- availability of services,

- speed.

Safety: protection of the entire flow of consignments and implementation of confidentiality of flows and of connections between nodes.

\subsection{Importance of infrastructure layer}

In modeling of the postal system we can not only consider the use of the layer model ISO / OSI, but we can find some parallels with transport systems of which an important feature is network character and availability of offer. The demand for postal services and its incidence in terms of place of origin is 
likewise characterized as in transport systems and electronic communication systems. It can be said that it is everywhere, but the offer of postal services as well as transport services is given by territorial or spatial restriction, which is specified by access points in the network - postal premises, mailboxes, postal machines (postal system) or in transport stations, bus stops and so on (transport system). Some types of services in the electronic communications are available without space limit, especially in the segment of mobile services [13].

Each postal network is made up of the respective stationary and mobile installations carrying out specified functions, without which it would be impossible to ensure the full operation of the network. Tasks of mobile devices of postal network are considered as transport media. Their primary role is to ensure regular connection between stationary devices distributed in the postal network. In terms of postal services, these devices are identified as postal courses. They are steadily organized connection established by transport route, with time data about the movement of vehicles used for transport of postal substrate. Stationary devices have a fixed, stable position in the network and through them the postal system ensures customer's requirements for individual service and carries out activities related to distribution of consignments (establishment of links between adjacent nodes) [14].

For postal systems it is typical to use hierarchical tree network configurations based on so called static route. It is the specifying of routes between regularly used network nodes, while the total set of nodes can be divided into inactive nodes, currently unused, and active nodes that are used as needed as transit points along the route. It means that in the postal transport network there are firmly established links between adjacent nodes in the network and defined routing between endpoints with the specified times of movement of the postal courses [15].

Configuration utilizing dynamic paths is typical by maximizing the flexibility of using a network structure with regard to the scope of requirements and by determining the size and solution of transport flows. The provider can choose from several connections in determining the route from point A to point B. This structure is often used when dealing with crisis situations such as unexpected interruptions in transport capacity and traffic collisions. Definition of the functions, tasks and rules for communication between different postal systems in the infrastructure part of the model permits consideration of the options for ensuring access to the postal operator network and mutual interoperability between postal systems [16].

A positive effect of the mutual interconnection of postal systems managed by different postal operators is support and strengthening of consumer interests through greater interoperability between operators. Aim of postal system interoperability is to build a monolithic block of services for users from subcomponents that are technically different and are managed by their different operators. Compatibility and interoperability of the postal systems enable increasing the efficiency of the provision of services such as applying components of automation of system to which is secured an access or ensuring compliance or increasing the quality of services as required [17]. In order to pursue interoperability we should remember three basic aspects: system organization and a hierarchy scope, legislative environment and standards applied [18].

\section{Conclusions}

An important reason why the authors consider the postal system as the layer model is increasingly wider range of services and their penetration into the field of electronic communications, which are becoming indispensable part of the provision of postal services, in particular in the form of additional services, which are increasing the positive perception from the customer. An interesting area is the creation of hybrid products involving ICT (Information Communication Technology) in the process of collection and distribution, when a part of the chain is realized electronically. Here, there is room for discussion, especially in the area of regulation of services. Which regulatory regime should apply to these services? What regulatory authority will deal with that? Which regulatory provisions or measures are unnecessary and which, in turn, are absent?

\section{Acknowledgements}

VEGA - 1/0721/15 Research on the impact of postal services and telecommunication convergence on regulatory approaches in the postal sector.

\section{References}

[1] ITA Consulting \& WIK-Consult (2009): The Evolution of the European Postal Market since 1997.

[2] WIK Consult/Jim Campbell (August 2013): Main Developments in the Postal Sector 2010-2013).

[3] HEITZLER, S.: Traditional Regulatory Approaches and the Postal Service Market, Competition and Regulation in Network Industries. Econ Papers, vol. 10, No. 1, 2009, 77-106. 
[4] KNIEPS, G, ZENHAUSERN, P., JAAG, C.: Wettbewerb und Universaldienst in europaischen Postmarkten, Fallstudien zur Netzokonomie, Wiesbaden: Gabler, 2009, 87-110.

[5] SVADlenKA, L., CHLAN, A.: Principles of the Proposed Czech Postal Sector Price Control Model. PROMET Traffic \& Transportation. Scientific J. on Traffic and Transportation Research. Sveuciliste u Zagrebu, Fakultet prometnih znanosti, Zagreb, vol. 21, No. 1, 2009, 33-40. ISSN 0353/5320.

[6] MADLENAKOVA, L., MADLENAK, R.: The Convergence of Telecommunication and Postal Services and their Impact on Regulatory Approaches, proc. of Reliability and statistics in transportation and communication (RelStat '15): the $15^{\text {th }}$ intern. conference, October 2015, Riga: Transport and Telecommunication Institute, 2015, 158-165, ISBN 978-9984-818-79-5.

[7] MAegli, M., JAAG, CH., KOLleR, M., TRINKNER, U.: Postal Markets and Electronic Substitution: What is the Impact of Convergence on Regulatory Practices and Institutions? ECPR conference: 'Regulation in the Age of Crisis', Dublin, 2010.

[8] MADLENAKOVA, L.: Layer Model of the Postal System, Habilitation Thesis, University of Zilina: Faculty of Operation and Economics of Transport and Communications, 2013, 112 p.

[9] VACULIK, J., TENGLER, J., MASLAK, O.: Application of EPC Standards and Mobile Networks Services to Enhance the Quality of Postal Service, Transport and telecommunication, vol. 16, No. 1, 2015, pp. 48-60, ISSN 1407-6160.

[10] KOLAROVSZKI, P.: Research of Readability and Identification of the Items in the Postal and Logistics Environment. Transport and Telecommunication, vol. 15, No. 3, 2014, 196-208, DOI: 10.2478/ttj-2014-0017, ISSN: 14076160.

[11] DROZDZIEL, P.: The Influence of the Vehicle Work Organization Conditions on the Engine Start-Up Parameters. Eksploatacja i Niezawodnosc, vol. 37, No. 1, 2008, 72-74, ISSN: 15072711.

[12] DROZDZIEL, P., KOMSTA, H., KRZYWONOS, L.: An Analysis of Unit Repair Costs as a Function of Mileage of Vehicles, A Selected Transport Company. Transport Problems, vol. 9, No. 4, 2014, 73-8. ISSN: 18960596.

[13] ZEMAN, D., MADLENAK, R.: Application of the OSI Reference Model in Terms of the Design Creation of Postal Transportation Networks. Perner's Contacts, vol. 5, No. 3, 2010, 422-429. ISSN 1801-674X.

[14] HRUDKAY, K., SESTAKOVA, S.: Management Systems of Intermodal Transport Terminals in Slovakia. Scientific and technical seminar Research activities in transport, construction and related fields, Herlany, January 2014, The Slovak Society of Logistics, ISBN 978-80-971604-6-3.

[15] MADLENAKOVA, L., MADLENAK, R.: Layer Model of the Postal System, Reliability and statistics in transportation and communication (RelStat' 14), October 2014, Riga: Transport and Telecommunication Institute, 106-113 ISBN 978-9984-818-70-2.

[16] PASTOR, O., TUZAR, A.: Theory of Transport Systems, ASPI Praha, 2007, ISBN 978-80-7357-285-3.

[17] BOLDRON, F., CREMER, H., DE DONDER, P., JORAM, D., ROY, B.: Network Externalities and the USO: A Two-sided Market Approach. Article in book: Progress in the Competitive Agenda in the Postal and Delivery Sector. Elgar, 2009, 184-195, ISBN 978-18484-4060-9.

[18] COREjova, T., Rostasova, M., Chrenkova, A., MAdudovA, E.: Regional Dimensions of Knowledge Processes, The Sector of Transport and Logistics and ICT in the Zilina Region, Communications - Scientific Letters of the University of Zilina, vol. 15, No. 2, 2013, 25-33, ISSN 1335-4205. 